\title{
Article \\ Clinical and Organizational Impacts of Medical Ordering Settings on Patient Pathway and Community Pharmacy Dispensing Process: The Prospective ORDHOSPIVILLE Study
}

\author{
Justine Clarenne 1,2,*D, Julien Gravoulet ${ }^{3,4}$, Virginie Chopard ${ }^{5}$, Julia Rouge ${ }^{5}$, Amélie Lestrille ${ }^{1}$, \\ François Dupuis $^{3}{ }^{\mathbb{D}}$, Léa Aubert ${ }^{1,2}$, Sophie Malblanc ${ }^{6}$, Coralie Barbe ${ }^{7}$, Florian Slimano ${ }^{1,2,+(\mathbb{D})}$ and \\ Céline Mongaret ${ }^{1,2,+}(\mathbb{D}$
}

1 Faculty of Pharmacy, Université de Reims Champagne-Ardenne, 51 Rue Cognacq-Jay, 51100 Reims, France; lestrille.amelie@gmail.com (A.L.); laubert@outlook.fr (L.A.); florian.slimano@univ-reims.fr (F.S.); celine.mongaret@univ-reims.fr (C.M.)

2 Department of Pharmacy, CHU Reims, Rue du Général Koenig, 51100 Reims, France

3 Faculty of Pharmacy, Université de Lorraine, 7 Avenue de la Forêt de Haye, 54500 Nancy, France; julien@gravoulet.fr (J.G.); francois.dupuis@univ-lorraine.fr (F.D.)

4 Pharmacie Gravoulet, 5 Rue du Haut Château, 54760 Leyr, France

5 OMéDIT Grand Est, 3 Boulevard Joffre, 54000 Nancy, France; Virginie.chopard@ars.sante.fr (V.C.); rouge.julia@gmail.com (J.R.)

6 Agence Régionale de Santé, 3 Boulevard Joffre, 54000 Nancy, France; sophie.malblanc@ars.sante.fr

7 Comité Universitaire de Ressources pour la Recherche en Santé, Pôle Santé, Université de Reims Champagne-Ardenne, 51 Rue Cognacq-Jay, 51100 Reims, France; coralie.barbe1@univ-reims.fr

Citation: Clarenne, J.; Gravoulet, J.; Chopard, V.; Rouge, J.; Lestrille, A.; Dupuis, F.; Aubert, L.; Malblanc, S.; Barbe, C.; Slimano, F.; et al. Clinical and Organizational Impacts of Medical Ordering Settings on Patient Pathway and Community Pharmacy Dispensing Process: The Prospective ORDHOSPIVILLE Study. Pharmacy 2022, 10, 2. https://doi.org/10.3390/ pharmacy10010002

Academic Editor: Paul Rutter

Received: 3 November 2021

Accepted: 20 December 2021

Published: 23 December 2021

Publisher's Note: MDPI stays neutral with regard to jurisdictional claims in published maps and institutional affiliations.

Copyright: (C) 2021 by the authors. Licensee MDPI, Basel, Switzerland. This article is an open access article distributed under the terms and conditions of the Creative Commons Attribution (CC BY) license (https:// creativecommons.org/licenses/by/ $4.0 /)$.
* Correspondence: clarenne.justine@gmail.com; Tel.: +33-03-2691-8284

+ The authors should be considered as co-last authors.

\begin{abstract}
During the dispensing process of medical orders (MOs), community pharmacists (CPs) can manage drug-related problems (DRPs) by performing pharmacist interventions (PIs). There is little evidence that the PI rate is higher with MOs from hospitals (MOHs) than ambulatory (MOAs) settings, and their impact on the patient and community pharmacy is unknown. The primary objective of this study was to compare the MOH and MOA PI rates. The secondary objective was to describe PIs and their clinical and organizational impacts on patient and community pharmacy workflow. A total of $120 \mathrm{CPs}$ participated in a prospective study. Each CP included $10 \mathrm{MOH}$ and $10 \mathrm{MOA}$ between January and June 2020. DRP and PI description and clinical and organizational impacts between $\mathrm{MOH}$ and MOA were assessed and compared. We analyzed $2325 \mathrm{MOs}$. PIs were significantly more frequent in $\mathrm{MOH}$ than in MOA $(9.7 \%$ versus $4.7 \% ; p<0.001)$. The most reported PI was the difficulty of contacting hospital prescribers $(n=45 ; 52.2 \%)$. MOHs were associated with a longer dispensing process time and a greater impact on patient pathway and community pharmacy workflow than MOAs. Lack of communication between hospital and primary care settings partly explains the results. Implementation of clinical pharmacy activities at patient discharge could alleviate these impacts.
\end{abstract}

Keywords: drug-related problems; community pharmacist; hospital discharge; pharmacist intervention; clinical impact; organizational impact

\section{Introduction}

A large part of the community pharmacist's working time is devoted to the dispensation of medical orders (MOs) for all types of patients, mainly coming from ambulatory or hospital settings [1]. Community pharmacists (CPs) are typically the first healthcare professionals to interact with recently discharged patients, which is a high-risk step in patient care pathway [2] or after hospital consultation.

During the dispensation process, CPs may detect drug-related problems (DRPs) [3] that they must manage and track by performing pharmacist interventions (PIs). In France, 
the French Society of Clinical Pharmacy (SFPC) developed and validated a reporting tool for the uniform detection and classification of pharmacist interventions in our hospitals [4]. In 2018, this tool was adapted by a group of experts designed by the SFPC for use in community pharmacy settings [5]. DRPs and PIs can be classified into eleven and seven categories, respectively. Additional DRPs can be detected on hospital Mos for several reasons such as the time of discharge, infrequently used or very expensive drugs (most of them unavailable immediately), and difficulties in calling prescribers [6-8]. Each DRP can not only result in clinical impacts for the patient but also in organizational impacts for community pharmacy teams (e.g., additional workload and difficulties related to professional task shifting) and patients (e.g., additional visits to the pharmacy).

In France, medical orders from hospital are reputed to be at high risk of drug-related problems (DRPs), but this is only based on the general feeling of community pharmacists. Only one study by Michel et al. reported the prevalence of DRPs detected by community pharmacists when dispensing hospital discharge prescriptions [2]. However, they did not compare these results with the prevalence of DRPs on MOAs. In order to characterize the potential specificities of DRPs on MOHs, especially in terms of clinical and organizational impact, we designed a prospective study at the regional level.

The primary objective of this study was to compare the rate of PIs performed by CPs between MOs issued from hospital (MOHs) or from ambulatory settings (MOAs). Then, the potential clinical relevance of these PIs, their potential clinical impact on patient care pathway, and the organizational impact on $\mathrm{CP}$ workflow were evaluated.

\section{Materials and Methods}

\subsection{Study Settings}

This is a prospective study organized by the Faculties of Pharmacy of Nancy (Université de Lorraine) and Reims (Université de Reims Champagne-Ardenne). The study was conducted in 120 community pharmacies in the Grand Est region, France. The details of pharmacy location (city-center pharmacy, neighborhood pharmacy, rural pharmacy, or pharmacy in shopping center) were not precisely collected, but repartition was supposed to be comparable to other regions in France. All the participating pharmacies were independent (there are no community pharmacy chains in France) and welcomed a pharmacy student during their last 6-month internship [9] under supervision of their mentor pharmacists. All mentor pharmacists had graduated at least five years ago and completed updated training each year before the 6-month internship formation. The inclusion period of medical orders lasted 6 months from January to June 2020. Due to the fact that the dispensation of medical orders from hospital setting (MOHs) is less frequent than medical orders from ambulatory settings (MOAs), each pharmacist included the 10 first $\mathrm{MOHs}$ they dispensed. Each inclusion of a $\mathrm{MOH}$ immediately resulted in the inclusion of the consecutive MOA they experienced at the pharmacy. A total of $10 \mathrm{MOHs}$ and $10 \mathrm{MOAs}$ were included in pairs for each community pharmacy.

This study was conducted in compliance with French legislation related to observational studies. Patient consent was obtained for all the subjects included in the study. Patients' records were anonymized prior to analysis. The database was constituted and collected in accordance with the reference methodology MR004 of the Commission Nationale de l'Informatique et des Libertés (no. 2212122, date: 3 July 2019). The study was declared at the national registry of health research (Health Data Hub) under number F20210907111038.

\subsection{Inclusion and Noninclusion Criteria}

Each medical order with at least one drug, medical device, and/or other health product was included. MOs from hospital settings (all types) were written after a medical consultation or hospital discharge (regardless of the hospitalization length). MOs from ambulatory settings could be written by a general practitioner or specialist.

Every MO with incomplete or duplicate electronic collection forms was excluded. 


\subsection{Data Recorded}

During the dispensation process, pharmacists detected DRPs for each $\mathrm{MOH}$ and MOA and then performed PIs according to the tool from the French Society of Clinical Pharmacy (SFPC) [3]. The potential clinical impact of each PI was prospectively assessed using the CLEOC tool from the SFPC [10]. For each MO, the pharmacists completed an electronic collection form (Supplementary Material) including 3 parts: information about $\mathrm{MO}$ (nature of the MO, identification of the individual bringing the MO to the pharmacy, nature and identification of the prescriber, and number of prescribed medications including medical devices and others); PI description (drug, DRP, outcome of the PI, and the potential clinical impact); and assessment of pharmaceutical care. Clinical impact was classified into 6 categories from harmful outcome of the PI (-1C) to lethal outcome avoidance for the patient (4C). Finally, the impacts on the patient care pathway and on community pharmacy workflow were assessed by using the delay of availability of the prescribed medications and the organizational impact on the patient's visit at the pharmacy.

\subsection{Statistical Analysis}

The chi-square test was used for the comparison of MOHs and MOAs. All statistical analyses were computed using $\mathrm{R}^{\circledR}$ (The $\mathrm{R}$ Project for Statistical Computing v.3.2.2). A $p$-value less than 0.05 was considered statistically significant.

\section{Results}

A total of 2325 prescriptions were included in the study: 1151 MOAs (49.5\%) and $1174 \mathrm{MOHs}(50.5 \%)$ from 120 community pharmacies (Table 1). Three MOAs and nine MOHs were excluded due to incomplete or duplicate collection form. Seven students provided less than 20 prescriptions, which resulted in 63 missing medical orders. Family caregiver and other relatives had to bring the $\mathrm{MO}$ to the community pharmacy significantly more frequently for MOHs than from MOAs $(n=366,(31.3 \%)$ and $n=166(14.4 \%)$, respectively; $p<0.001)$. Difficulty in prescriber identification was significantly more frequent for MOHs than for MOAs $(4.8 \%$ versus $0.5 \% ; p<0.001)$.

Descriptions of DRPs and PIs and comparisons between MOA and MOH are shown in Table 2. A total of 169 DRPs were detected by CPs. DRPs were significantly more frequent for MOHs than for MOAs $(\mathrm{n}=114(9.7 \%)$ vs. $\mathrm{n}=55(4.8 \%) ; p<0.001)$. There were 99 hospital prescriptions $(8.4 \%)$ and 53 ambulatory prescriptions $(4.6 \%)$ with at least one DRP. The most frequent DRPs were improper prescription $(n=61,36.1 \%)$ and dosage problems ( $\mathrm{n}=42,24.9 \%$ ). There was no difference in DRP and PI subtype frequencies depending on the MO setting. The PI acceptance rate by the prescriber was 58.2\% (MOAs) and 62.2\% (MOHs), with no significant differences. Major or lethal potential clinical impacts tended to be more frequent for MOAs than for MOHs $(\mathrm{n}=13(24.5 \%)$ vs. $\mathrm{n}=12(12.4 \%) ; p=0.056)$.

\subsection{Impact on Patient Care Pathway}

Unplanned consequences for patients were significantly more frequent for MOHs than for MOAs $(7.4 \%$ vs. $3.0 \%$; $p<0.001)$, mainly due to the delay for the initiation of a new drug $(p<0.001)$ (Table 3$)$. Immediate nondispensed MOs were significantly more frequent for MOHs than for MOAs $(20.6 \%$ vs. $6.3 \% ; p<0.001)$. In case of delayed dispensation, the dispensation occurred mainly within $24 \mathrm{~h}(80.8 \%)$ without differences between MOAs $(75.0 \%)$ and MOHs (82.7\%). Patient burden was assessed as minor by community pharmacists in most cases $(82.2 \%)$ without differences between MOHs $(86.1 \%)$ and MOAs $(81.0 \%)$. For five $(2.0 \%) \mathrm{MOHs}$, the impact was rated as major by the $\mathrm{CP}$ when the patient had to return to the pharmacy when there was a long distance between the $\mathrm{CP}$ and the patient's home. 
Table 1. Description of the regulatory overview of the 2325 medical orders collected during the study period.

\begin{tabular}{|c|c|c|c|c|}
\hline \multirow{2}{*}{ Variable $^{a}$} & MOs & MOs from Ambulatory Setting & MOs from Hospital Setting & \multirow{2}{*}{$p$-Value } \\
\hline & $\mathrm{n}=2325$ & $\mathrm{n}=1151$ & $\mathrm{n}=1174$ & \\
\hline \multicolumn{5}{|c|}{$\begin{array}{l}\text { Individual bringing the MO to the } \\
\text { community pharmacy }\end{array}$} \\
\hline Patient & $1683(72.4)$ & $938(81.5)$ & $745(63.3)$ & \multirow{4}{*}{$p<0.001$} \\
\hline Family caregiver/relatives & $532(22.9)$ & $166(14.4)$ & $366(31.3)$ & \\
\hline Professional caregiver & $47(2.0)$ & $18(1.6)$ & $29(2.5)$ & \\
\hline Sent by email or fax & $63(2.7)$ & $29(2.5)$ & $34(2.9)$ & \\
\hline \multicolumn{5}{|l|}{ Status of the prescriber } \\
\hline Graduated physician & $1977(85.0)$ & $1102(95.8)$ & $875(74.4)$ & \multirow{5}{*}{$p<0.001$} \\
\hline Medicine resident & $152(6.5)$ & $6(0.5)$ & $146(12.4)$ & \\
\hline Other ${ }^{b}$ & $40(1.7)$ & $20(1.7)$ & $20(1.7)$ & \\
\hline Nonidentified & $75(3.2)$ & $1(0.1)$ & $74(6.3)$ & \\
\hline Discrepancy $^{c}$ & $83(3.6)$ & $22(1.9)$ & $61(5.2)$ & \\
\hline \multicolumn{5}{|l|}{$\begin{array}{l}\text { Prescriber identification: } \\
\text { identity (surname) }\end{array}$} \\
\hline Easy to identify & $2263(97.3)$ & 1145 (99.5) & $1118(95.4)$ & \multirow{3}{*}{$p<0.001$} \\
\hline Hard to identify & $34(1.5)$ & $4(0.3)$ & $30(2.6)$ & \\
\hline Not possible to identify & $28(1.2)$ & $2(0.2)$ & $26(2.2)$ & \\
\hline
\end{tabular}

MO: medical order; $n$ : number; ${ }^{a}$ results presented as number $(\%){ }^{b}$ other authorized health professional: nurses, dentist, kinesiologist, or midwife; ${ }^{c}$ discrepancy between the header in the prescription form and signature; $\mathrm{d}$ comparison between non-identified prescriber, discrepancy, and other prescriber statuses. The bracket symbol shows the variables involved in the statistical test and the $p$-value.

Table 2. Description of the 169 DRPs and PIs from 152 MOs according to the French Society of Clinical Pharmacy and the CLEO Tool.

\begin{tabular}{|c|c|c|c|}
\hline Variable $^{a}$ & $\begin{array}{l}\text { DRPs on All MOs } \\
\quad(n=169)\end{array}$ & $\begin{array}{l}\text { DRPs on MOs from } \\
\text { Ambulatory Setting } \\
\qquad(\mathrm{n}=55)\end{array}$ & $\begin{array}{l}\text { DRPs on MOs from } \\
\text { Hospital Setting } \\
(\mathrm{n}=114)\end{array}$ \\
\hline \multicolumn{4}{|l|}{ Drug-related problem } \\
\hline Improper prescription & $61(36.1)$ & $11(20.0)$ & $50(43.9)$ \\
\hline Dosage problem & $42(24.9)$ & $15(27.3)$ & $27(23.7)$ \\
\hline Drug interaction & $11(6.5)$ & $6(10.9)$ & $5(4.4)$ \\
\hline $\begin{array}{c}\text { Drug or medical device not received by } \\
\text { the patient }\end{array}$ & $15(8.9)$ & $6(10.9)$ & $9(7.9)$ \\
\hline Drug omission & $13(7.7)$ & $6(10.9)$ & $7(6.1)$ \\
\hline $\begin{array}{l}\text { Contraindication/nonconformity to } \\
\text { guidelines }\end{array}$ & $9(5.3)$ & $5(9.1)$ & $4(3.5)$ \\
\hline Therapeutic redundancy & $9(5.3)$ & $2(3.6)$ & $7(6.1)$ \\
\hline Unjustified drug prescription & $7(4.1)$ & $3(5.5)$ & $4(3.5)$ \\
\hline Adverse drug reaction & $2(1.2)$ & $1(1.8)$ & $1(0.9)$ \\
\hline \multicolumn{4}{|l|}{ Pharmacist intervention } \\
\hline Dose adjustment & $47(27.8)$ & $16(29.1)$ & $31(27.3)$ \\
\hline $\begin{array}{l}\text { Optimization of the } \\
\text { dispensing/administration mode }\end{array}$ & $43(25.4)$ & $10(18.2)$ & $33(29.0)$ \\
\hline Discontinuation or refusal to deliver & $30(17.8)$ & $9(16.4)$ & $21(18.5)$ \\
\hline Drug switch & $25(14.8)$ & $14(25.4)$ & $11(9.6)$ \\
\hline Addition of a new drug & $18(10.7)$ & $6(10.9)$ & $12(10.4)$ \\
\hline Choice of administration route & $3(1.8)$ & 0 & $3(2.6)$ \\
\hline Drug monitoring & $3(1.8)$ & 0 & $3(2.6)$ \\
\hline
\end{tabular}


Table 2. Cont.

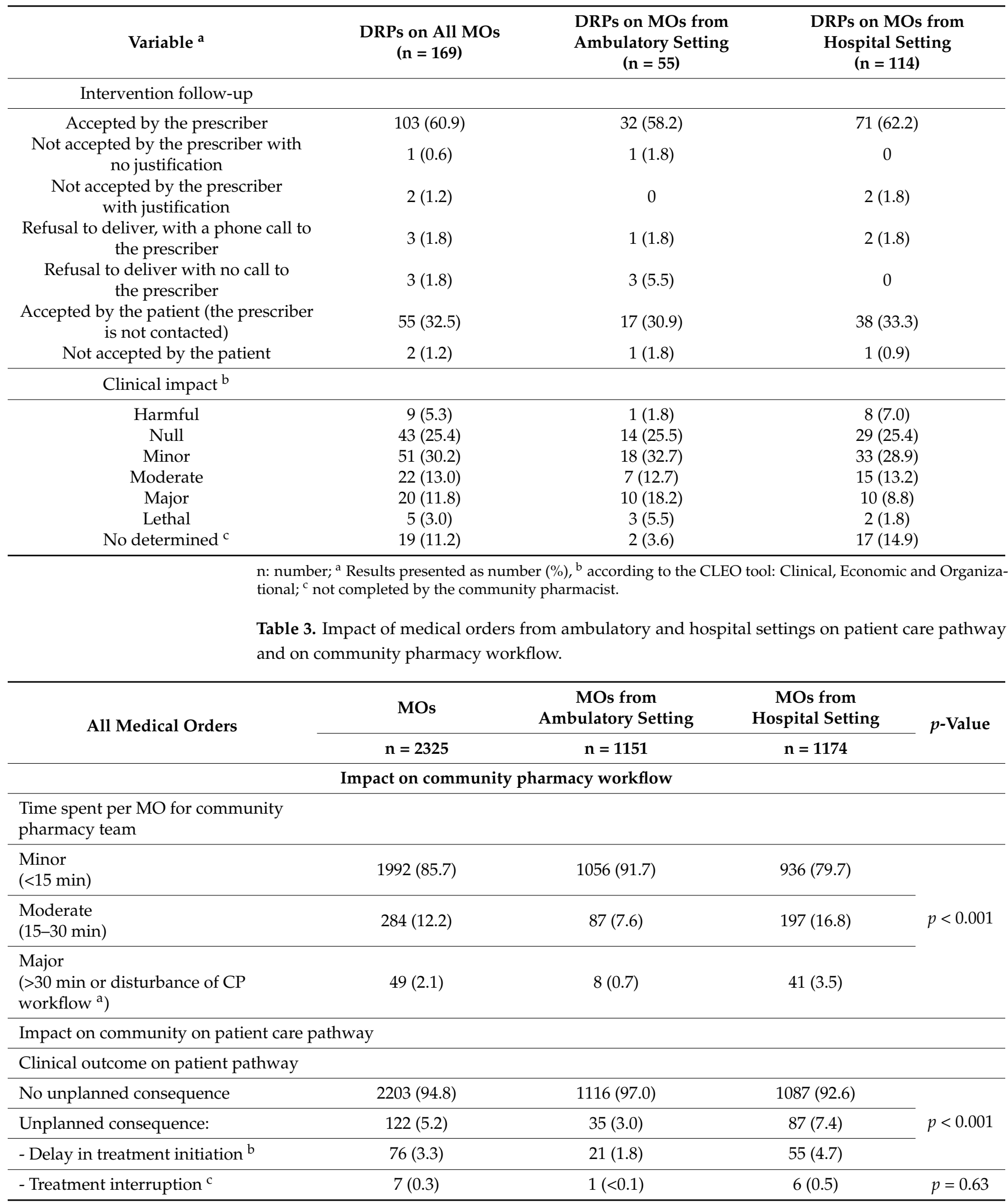


Table 3. Cont.

\begin{tabular}{|c|c|c|c|c|}
\hline \multirow[t]{2}{*}{ All Medical Orders } & MOs & $\begin{array}{c}\text { MOs from } \\
\text { Ambulatory Setting }\end{array}$ & $\begin{array}{c}\text { MOs from } \\
\text { Hospital Setting }\end{array}$ & \multirow[t]{2}{*}{$p$-Value } \\
\hline & $\mathrm{n}=2325$ & $\mathrm{n}=1151$ & $\mathrm{n}=\mathbf{1 1 7 4}$ & \\
\hline \multicolumn{5}{|c|}{ Impact on community pharmacy workflow } \\
\hline $\begin{array}{l}\text { - Referral to the } \\
\text { GP/attending physician }\end{array}$ & $7(0.3)$ & $2(0.2)$ & $5(0.4)$ & \\
\hline - Other & $32(1.4)$ & $11(1.0)$ & $21(1.8)$ & \\
\hline Non immediate dispensed $\mathrm{MO}$ & $314(13.5)$ & $72(6.3)$ & $242(20.6)$ & $p<0.001$ \\
\hline \multicolumn{5}{|c|}{$\begin{array}{l}\text { Delay for availability of medicine in } \\
\text { case of nonimmediate dispensing }\end{array}$} \\
\hline In the half-day & $116(36.9)$ & $28(38.9)$ & $88(36.4)$ & \multirow{3}{*}{$p=0.21$} \\
\hline Within $24 \mathrm{~h}$ & $138(43.9)$ & $26(36.1)$ & $112(46.3)$ & \\
\hline Beyond $24 \mathrm{~h}$ & $60(19.1)$ & $18(25.0)$ & 42 (17.3) & \\
\hline \multicolumn{5}{|l|}{$\begin{array}{l}\text { Patient burden in case of } \\
\text { non-immediate dispensed MO }\end{array}$} \\
\hline Minor ${ }^{d}$ & $258(82.2)$ & $62(86.1)$ & $196(81.0)$ & $p=0.32$ \\
\hline Moderate $^{\mathrm{e}}$ & $51(16.2)$ & $10(13.9)$ & $41(17.0)$ & \\
\hline Major $^{f}$ & $5(1.6)$ & 0 & $5(2.0)$ & \\
\hline & \multicolumn{4}{|c|}{$\begin{array}{l}\mathrm{n} \text { : number; }{ }^{\mathrm{a}} \text { For example, unplanned necessity for community pharmacist to travel another pharmacy/supplier } \\
\text { for medicine supply; }{ }^{\mathrm{b}} \text { delay in the initiation of a medicine (e.g., because of unavailability, lack of information, etc.) } \\
{ }^{\mathrm{c}} \text { interruption of medicine consumption (e.g., from hospital to ambulatory setting) because of the unavailability } \\
\text { of medicine, for example; }{ }^{\mathrm{d}} \text { minimal burden (community pharmacy close to patient home or mobile patient) } \\
{ }^{\mathrm{e}} \text { Moderate burden (CP distant from the patient home and/or less mobile patient); }{ }^{\mathrm{f}} \text { Major burden (CP distant } \\
\text { from patient home and immobile patient). The bracket symbol shows the variables involved in the statistical test } \\
\text { and the } p \text {-value. "." is to distinguish the subcategories of unplanned consequence. }\end{array}$} \\
\hline
\end{tabular}

\subsection{Impact on Community Pharmacy Workflow}

The impact on community pharmacy workflow is presented in Table 3. Time-consuming activities $>30 \mathrm{~min}$ or disturbed $\mathrm{CP}$ team activities were more frequent for $\mathrm{MOHs}$ than for MOAs $(20.3 \%$ vs. $8.3 \% ; p<0.001)$. Difficulties in contacting prescribers were significantly more frequent for MOHs than for MOAs $(52.2 \%$ vs. $16.7 \% ; p<0.001)$ with an average of two or three interlocutors before obtaining the lacking information.

\section{Discussion}

Our study has limitations. Among them, the drug names involved in the DRPs and PIs were neither collected nor reviewed. Additionally, the significance of the interactions was only assessed by pharmacy students and their mentor. The investigators did not perform a secondary analysis on medical orders or pharmacist interventions. Moreover, clinical data were not collected during our study.

Nevertheless, to date, this study is the first to conduct a comparison of DRPs and PIs on MOs provided from both hospital and ambulatory settings considering clinical and organizational impact on patient care pathway and the workflow of the CP teams. Our study highlighted that MOs from hospital settings generate more PIs than medical orders from ambulatory settings. The students reported $8.3 \%$ and $4.6 \%$ of DRPs for MOs from hospital and ambulatory settings, respectively. This DRP rate detection is in line with previous studies that reported a DRP rate of $0.26 \%$ to $7 \%$ [11-18]. With nearly twice as many DRPs on MOHs than on MOAs, prescriptions from hospitals seem to cause more problems during the dispensing process. The same observation was reported in a Norwegian study also comparing hospital and ambulatory care prescriptions, with DRPs in $7.1 \%$ for $\mathrm{MOHs}$ versus $1.5 \%$ for MOAs [11]. 
The most frequently reported DRP is related to improper prescription, such as a lack of clarity or missing prescriber information. This category included regulatory admissibility, which was statistically lower for MOHs in our study. In practice, prescribers from ambulatory care have their name and licence number on their own prescription paper, unlike hospital prescribers (mostly medicine residents) using prescription papers displaying only the department's name. This lack of identification information results in nonadmissibility or admissibility after a minor correction. Similar results were also found in another French study where the name of the physician was unspecified on one-third of the medical orders dispensed by the CPs [5]. Nevertheless, this problem should decrease with the emergence of computerized discharge orders. The frequencies of the two main DRPs showed no significant difference according to the setting and are in agreement with those reported in previous studies $[5,11,19,20]$.

A major aspect of the dispensation process is information availability when needed. Two difficulties were highlighted for MOHs: Firstly, MOHs are more often brought by a relative or a professional caregiver (after hospital discharge) than by the patient. These third parties might lack information regarding the patient's condition, history, and/or administrative information. Secondly, CPs reported difficulty in contacting the $\mathrm{MOH}$ prescriber. The same observation was reported by Trausch and Green in 2017 with at least two interlocutors for $48 \%$ of hospital calls [7]. Efforts are needed to improve the availability of patient data to CPs (e.g., by sharing electronic healthcare records out of the hospital setting). Despite these difficulties in reaching the prescribers, the acceptance rate of PIs by the prescriber or the patient for some minor DRPs was over $90 \%$, which should be considered a good indicator of PI relevance in this study; PI acceptance rate in comparable studies ranged from $66 \%$ to $94 \%[6,19]$.

This study reported the potential clinical impact of PIs on patient care pathway and on $\mathrm{CP}$ workflow related to MOs from the hospital or ambulatory settings separately. For the potential clinical impact of PIs, a trend toward a higher number of PIs with major or lethal impact was found for MOAs than for MOHs. Although not reaching statistical significance, these results confirm that the more frequent occurrence of DRPs for MOHs is not correlated to their potential clinical impact.

For the patient care pathway, MOHs are associated with more unplanned consequences for the patient and nonimmediate-dispensed MOs, even for MOs without DRPs. We hypothesize that this finding is linked with unfrequently used and/or very expensive prescribed drugs such as treatments for rare disease conditions (orphan disease), including targeted therapies for cancers. In 2016, Michel et al. also reported the problem of delayed treatment initiation with $23.4 \%$ of DRPs occurring due to a drug being out of stock [4]. This delay can then result in noncompliance with the treatment or an additional visit to the pharmacy for the patient. The problem of out-of-stock drugs may be anticipated by having the hospital pharmacist perform a medication reconciliation at hospital discharge. This key step recently showed its benefits in terms of DRP exposure and severe iatrogenic problems [16].

The organizational consequences for CPs, mostly related to the time spent per MO, were also significantly different according to the setting. Nevertheless, time spent by the $\mathrm{CP}$ team was less than $15 \mathrm{~min}$ for the majority of MOs, which agrees with two previous studies that found extra time to complete the MOs to be less than 5 min [11,21]. As studies found that out-of-stock drugs are frequently involved in extended time before treatment initiation, one solution could be the optimization of the communication between hospital and community pharmacists. This system has been developed in the field of oral anticancer drugs by the implementation of pharmaceutical care [22].

Finally, our study highlights a lack of communication between hospital practitioners (including hospital pharmacists) and community pharmacists. Our results provide an accurate comparison between DRPs from ambulatory and from hospital settings, not only focusing on patients from the hospital. In 2017, the French Society of Clinical Pharmacy (SFPC) proposed a new model of clinical pharmacy for France, which is based on the 
implementation of personal pharmaceutical plans dedicated to management adapted to the patient's pathway. It includes the performance of medication reconciliation at patient discharge by ensuring collaboration between hospital and community pharmacists. This process has not been systematically implemented for all patients (hospital discharge or post consultation) due to a lack of human resources. However, two French studies have highlighted the benefit of medication reconciliation at discharge [23,24]. In order to enhance the communication level without relying exclusively on the hospital pharmacist, one option is the implementation of the status of "corresponding pharmacist" that has been recently authorized by a French national law [25]. Given the recognition of this new status, community pharmacists could be assigned new competencies for adjustments or switches from one drug to another, which may limit the need of hospital contact. Moreover, recognition of the corresponding pharmacist by the hospital could allow the pharmacist to send all correspondence such as hospital consultation letters or hospital discharge letters, as was already claimed [26]. Some countries such as Ohio (United States of America), Canada, and United Kingdom have already implemented programs to enhance the transition in care with positive results on patients [27] and less hospital readmissions, respectively [28,29]. For a few months in the United Kingdom, a program named Transfers of Care Around Medicines (TCAM) uses an online platform to transfer the discharge information to the community pharmacy chosen by the patient, which can contact him for a follow-up [30]. An increase in such programmes is to be expected in future years to improve the coordination and continuity of outpatient care.

\section{Conclusions}

Most of the problems reported in this study, especially those related to the admissibility of MOHs, seem avoidable with the implementation of simple measures such as the use of assistive prescription software. Communication between community pharmacists, general practitioners, and hospital clinicians appears essential for the continuity of care and to make the dispensing process more fluid. The implementation of community and hospital pharmacist communication as a whole or a part of medication reconciliation at hospital discharge is probably the most accessible measure to implement, but whether resources are available remains questionable.

Supplementary Materials: The following are available online at https://www.mdpi.com/article/ 10.3390/pharmacy10010002/s1, File S1: Information collection form used at the community pharmacy, File S2: ORDHOSPIVILLE study design flow chart.

Author Contributions: Conceptualization, J.C., J.G., V.C., J.R., A.L., L.A., S.M., F.S. and C.M.; methodology, J.C., J.G., V.C.; J.R., A.L., F.D., L.A., S.M., F.S. and C.M.; software, J.G.; validation, J.G., V.C., A.L., F.D., F.S. and C.M.; formal analysis, J.C. and V.C.; investigation, J.C., J.G., A.L., L.A., F.S. and C.M.; data curation, J.C. and J.G.; writing—original draft preparation, J.C., F.S. and C.M.; writingreview and editing, J.C., J.G., V.C., J.R., A.L., F.D., L.A., S.M., C.B., F.S. and C.M.; visualization, C.B.; supervision, J.G., F.S. and C.M.; project administration, J.G., F.D., F.S. and C.M. All authors have read and agreed to the published version of the manuscript.

Funding: This research received no external funding.

Institutional Review Board Statement: Not applicable.

Informed Consent Statement: Informed consent was obtained from all subjects involved in the study.

Data Availability Statement: The data presented in this study are available on request from the corresponding author. The data are not publicly available due to privacy.

Acknowledgments: We thank all pharmacist students and their mentors for their help in the study's investigations.

Conflicts of Interest: The authors declare no conflict of interest. 


\section{References}

1. Lourenço, L.; Van Mil, J.W.F.; Henman, M. Pharmaceutical Care and Dispensing Medicines. In The Pharmacist Guide to Implementing Pharmaceutical Care; Springer: Cham, Switzerland, 2019; pp. 251-259. [CrossRef]

2. Michel, B.; Hemery, M.; Rybarczyk-Vigouret, M.-C.; Wehrle, P.; Beck, M. Drug-dispensing problems community pharmacists face when patients are discharged from hospitals: A study about 537 prescriptions in Alsace. Int. J. Qual. Health Care 2016, 28, 779-784. [CrossRef]

3. Dooley, M.J.; Allen, K.M.; Doecke, C.J.; Galbraith, K.; Taylor, G.R.; Bright, J.; Carey, D.L. A prospective multicentre study of pharmacist initiated changes to drug therapy and patient management in acute care government funded hospitals. Br. $J$. Clin. Pharmacol. 2004, 57, 513-521. [CrossRef]

4. $\quad$ Allenet, B.; Bedouch, P.; Rose, F.-X.; Escofier, L.; Roubille, R.; Charpiat, B.; Juste, M.; Conort, O. Validation of an instrument for the documentation of clinical pharmacists interventions. Pharm. World Sci. 2006, 28, 181-188. [CrossRef]

5. Vo, T.H.; Bardet, J.; Charpiat, B.; Leyrissoux, C.; Gravoulet, J.; Allenet, B.; Conort, O.; Bedouch, P. Validation of a tool for reporting pharmacists' interventions in everyday community pharmacy. J. Clin. Pharm. Ther. 2017, 43, 240-248. [CrossRef]

6. Paulino, E.I.; Bouvy, M.L.; Gastelurrutia, M.A.; Guerreiro, M.; Buurma, H. Drug related problems identified by European community pharmacists in patients discharged from hospital. Pharm. World Sci. 2004, 26, 353-360.

7. Trausch, N.; Green, J.A. Direct observation of telephone communication between community pharmacies and prescribers in New Zealand. Int. J. Clin. Pharm. 2018, 40, 1005-1009. [CrossRef]

8. Brühwiler, L.D.; Hersberger, K.E.; Lutters, M. Hospital discharge: What are the problems, information needs and objectives of community pharmacists? A mixed method approach. Pharm. Pract. 2017, 15, 1046. [CrossRef]

9. Bourdon, O.; Ekeland, C.; Brion, F. Pharmacy Education in France. Am. J. Pharm. Educ. 2008, 72, 132. [CrossRef]

10. Vo, H.T.; Charpiat, B.; Chanoine, S.; Juste, M.; Roubille, R.; Rose, F.-X.; Conort, O.; Allenet, B.; Bedouch, P. CLEO: A multidimensional tool to assess clinical, economic and organisational impacts of pharmacists' interventions. Eur. J. Hosp. Pharm. 2021, 28, 193-200. [CrossRef]

11. Haavik, S.; Soeviknes, S.; Erdal, H.; Kjonniksen, I.; Guttormsen, A.B.; Granas, A.G. Prescriptions from general practitioners and in hospital physicians requiring pharmacists' interventions. Pharmacoepidemiol. Drug Saf. 2010, 20, 50-56. [CrossRef]

12. Chen, Y.-F.; Neil, K.E.; Avery, A.J.; Dewey, M.E.; Johnson, C. Prescribing errors and other problems reported by community pharmacists. Ther. Clin. Risk Manag. 2005, 1, 333-342.

13. Knudsen, P.; Herborg, H.; Mortensen, A.R.; Knudsen, M.; Hellebek, A. Preventing medication errors in community pharmacy: Frequency and seriousness of medication errors. Qual. Saf. Health Care 2007, 16, 291-296. [CrossRef]

14. Ekedahl, A. Problem prescriptions in Sweden necessitating contact with the prescriber before dispensing. Res. Soc. Adm. Pharm. 2010, 6, 174-184. [CrossRef]

15. Volmer, D.; Haavik, S.; Ekedahl, A. Use of a generic protocol in documentation of prescription errors in Estonia, Norway and Sweden. Pharm. Pract. 2012, 10, 72-77. [CrossRef]

16. Bishop, L.D.; Young, S.W.; Conway, A. Interventions performed by community pharmacists in one Canadian province: A cross-sectional study. Ther. Clin. Risk Manag. 2012, 8, 415-421. [CrossRef]

17. Pottegård, A.; Hallas, J.; Søndergaard, J. Pharmaceutical interventions on prescription problems in a Danish pharmacy setting. Int. J. Clin. Pharm. 2011, 33, 1019-1027. [CrossRef]

18. Castronovo, A.; Gervais, F.; Mongaret, C.; Slimano, F. Pharmacists' interventions on prescription problems in one French community pharmacy: A prospective pilot study. Ann. Pharm. Francaises 2018, 76, 299-305. [CrossRef]

19. Ensing, H.T.; Koster, E.S.; Van Berkel, P.I.; Van Dooren, A.A.; Bouvy, M.L. Problems with continuity of care identified by community pharmacists post-discharge. J. Clin. Pharm. Ther. 2016, 42, 170-177. [CrossRef]

20. Mongaret, C.; Aubert, L.; Lestrille, A.; Albaut, V.; Kreit, P.; Herlem, E.; Noel, N.; Touré, F.; Lallier, F.; Slimano, F.; et al. The Role of Community Pharmacists in the Detection of Clinically Relevant Drug-Related Problems in Chronic Kidney Disease Patients. Pharmacy 2020, 8, 89. [CrossRef]

21. Westerlund, T.; Almarsdottir, A.B.; Melander, A. Drug-related problems and pharmacy interventions in community practice. Int. J. Pharm. Pract. 1999, 7, 40-50. [CrossRef]

22. Dalby, M. Current models of support from community pharmacies for patients on oral anticancer medicines. J. Oncol. Pharm. Pract. 2017, 25, 140-147. [CrossRef]

23. Pourrat, X.; Leyrat, C.; Allenet, B.; Bouzige, B.; Develay, A.; Fraysse, M.; Garnier, V.; Halimi, J.; Roux-Marson, C.; Giraudeau, B. Effectiveness of a multicomponent pharmacist intervention at hospital discharge for drug-related problems: A cluster randomised cross-over trial. Br. J. Clin. Pharmacol. 2020, 86, 2441-2454. [CrossRef]

24. Van Hollebeke, M.; Talavera-Pons, S.; Mulliez, A.; Sautou, V.; Bommelaer, G.; Abergel, A.; Boyer, A. Impact of medication reconciliation at discharge on continuity of patient care in France. Int. J. Clin. Pharm. 2016, 38, 1149-1156. [CrossRef]

25. Décret $n^{\circ}$ 2021-685 du 28 Mai 2021 Relatif au Pharmacien Correspondant. Journal Officiel du 30 Mai 2021. Available online: https:/ / www.legifrance.gouv.fr/jorf/id/JORFTEXT00004355S8014 (accessed on 3 December 2021).

26. Abbass, A. Why community pharmacy should receive the hospital discharge letter. Pharm. J. 2020, 304, 7938. [CrossRef]

27. Luder, H.R.; Frede, S.M.; Kirby, J.A.; Epplen, K.; Cavanaugh, T.; Martin-Boone, J.E.; Conrad, W.F.; Kuhlmann, D.; Heaton, P.C. TransitionRx: Impact of community pharmacy postdischarge medication therapy management on hospital readmission rate. J. Am. Pharm. Assoc. 2015, 55, 246-254. [CrossRef] 
28. Guilcher, S.J.T.; Fernandes, O.; Luke, M.; Wong, G.; Lui, P.; Cameron, K.; Pariser, P.; Raco, V.; Kak, K.; Varghese, S.; et al. A developmental evaluation of an intraprofessional Pharmacy Communication Partnership (PROMPT) to improve transitions in care from hospital to community: A mixed-methods study. BMC Health Serv. Res. 2020, 20, 99. [CrossRef]

29. Nazar, H.; Brice, S.; Akhter, N.; Kasim, A.; Gunning, A.; Slight, S.P.; Watson, N.W. New transfer of care initiative of electronic referral from hospital to community pharmacy in England: A formative service evaluation. BMJ Open 2016, 6, e012532. [CrossRef]

30. Transfers of Care Around Medicines (Discharge Medicines Service). East Midlands Academic Health Science Network. Available online: https://emahsn.org.uk/our-work/innovations/transfers-of-care-around-medicines-tcam (accessed on 9 December 2021). 